\title{
Development of a solar energy meter for an experimental array
}

\author{
Roman Ivanov ${ }^{1}$, Nikita Maksakov ${ }^{1, *}$ \\ ${ }^{1}$ Melentiev Energy Systems Institute SB RAS, Russia
}

\begin{abstract}
The relevance of the presented development is due to the need to create a device to read and process information from an experimental array of solar panels. The purpose of the array is to obtain reliable data for the verification of models for estimating photovoltaic power potential indicators used in justifying the feasibility of the adoption of solar power plants in the eastern regions of Russia. We present a description of the main and auxiliary equipment of the experimental array. The array's solar panels are arranged in different ways so as to determine the most efficient tilt angle and justify the need for building a sun-tracking system. The proprietary device based on the Arduino microcontroller was designed to read and write the value of instantaneous power of solar panels. The sensor that will monitor the amperage is ACS712, which is connected to the gap of the power circuit. The study provides a diagram of the current meter and describe its operation. We outline the main stages of subsequent data processing.
\end{abstract}

\section{Relevance of the study}

The widespread adoption of photovoltaic power plants based on solar panels for various applications requires scientific and economic justification. This is necessary for both the design of new plants and modernization of already operating plants [1-3]. The validity of the estimate of solar radiation in the region in question is important for the above justification. Obtaining such data involves processing and comparing the results of theoretical and experimental studies.

Data on solar radiation incident on the surface of land-based weather stations that are horizontal or perpendicular to the sun are given in climate handbooks and are also publicly available on the Internet [4-5]. Some disadvantages of the data obtained in this way should be noted. Reference information from land-based weather stations is naturally more accurate than satellite data. Having said that, reference books have not been published for a long time; the last edition dates back to 1991. [6]. Moreover, the network of weather stations is quite sparse, which can lead to assuming the data that are known to be incorrect when considering the consumer away from the weather station.

Therefore, in the best practices of today, an estimate of solar radiation incident on the horizontal surface can be derived from climatic data using computational models: i.e., parametric and decomposition models. Parametric models require detailed information on numerous climatic parameters: type, number, and distribution of clouds, atmospheric turbidity, atmospheric pressure, deposited thickness of water vapor in the atmosphere, etc. [7].
Decomposition models use a limited set of measurements that are carried out at most weather stations: data on the total solar radiation incident on the horizontal surface, on the daily duration of sunshine, temperature, cloud cover, and relative humidity [8].

The main purpose of the study is to develop a device to process the information on the power of solar panels in real-time so as to verify the results of modeled calculations to estimate the photovoltaic power potential indicators values. Due to the fact that most units collect only aggregate data on electric power generation and have different technological content, it is not reasonable to compare such data and justify decisions based on them.

\section{Description of the experimental photovoltaic array}

To obtain our own dataset, we have designed and installed an experimental array of solar panels at the Melentiev ESI, SB RAS. The main purpose of the photovoltaic array is to obtain reliable information to assess the efficiency of the use of solar power plants for different regions, to justify the optimal tilt angle of the panels and the need to build an automated sun-tracking system. Similar studies are carried out by researchers at other institutions as well [9].

The array consists of three photovoltaic stations whose panels are mounted on a common frame. To install the panels, a dedicated steel structure is mounted. The array is installed on the roof of the building of the experimental unit and is designed for carrying out experimental work to monitor the output indicators of solar panels installed in different orientations.

Corresponding author: nikita.max @isem.irk.ru 
The main equipment of the experimental array consists of three individual solar panels, each of which is attached in a different way:

- with a fixed tilt angle in relation to the sun;

- with manual change of the tilt angle (in the vertical direction);

- with a system of tracking the sun in two planes.

The fixed tilt angle of the first panel is equal to the latitude of Irkutsk, which is 52 degrees. For the second panel, there is a mechanism installed for manually changing the tilt angle according to the seasons of the year. The third panel is controlled to track the sun by a dedicated mechanism, a dual-axis solar tracker. The general view of the main and auxiliary equipment of the experimental array is shown in Figures 1 and 2.

Each panel is equipped with auxiliary equipment: a hybrid inverter (a charge controller and inverter installed in a single housing) and a battery array. Table 1 shows the main specifications of the installed hybrid inverters. All inverters are short-circuit-proof, the rated input voltage is $24 \mathrm{~V}$ and the output voltage waveform is a pure sine.

Table 1. Main specifications of the installed inverters

\begin{tabular}{|c|c|c|c|}
\hline \multirow[b]{2}{*}{$\begin{array}{c}\text { Technical } \\
\text { specifications }\end{array}$} & \multicolumn{3}{|c|}{ Inverter name } \\
\hline & $\begin{array}{c}\text { UMX-NG } \\
\text { Plus } 2 \\
\text { KWA } \\
\text { MPPT }\end{array}$ & $\begin{array}{c}\text { Epever } \\
\text { SHI1000- } \\
22\end{array}$ & $\begin{array}{c}\text { Epsolar } \\
\text { UP2000, } \\
\text { M3322 }\end{array}$ \\
\hline $\begin{array}{c}\text { Frequency, } \\
\mathrm{Hz}\end{array}$ & $50 / 60$ & 50 & $50 / 60$ \\
\hline $\begin{array}{c}\text { Output } \\
\text { voltage, } \mathrm{V}\end{array}$ & $230 \pm 5 \%$ & $\begin{array}{l}220 / 230 \\
\text { (switch) }\end{array}$ & $220 \pm 3 \%$ \\
\hline $\begin{array}{l}\text { Maximum } \\
\text { efficiency }\end{array}$ & 95 & 94 & 95 \\
\hline
\end{tabular}

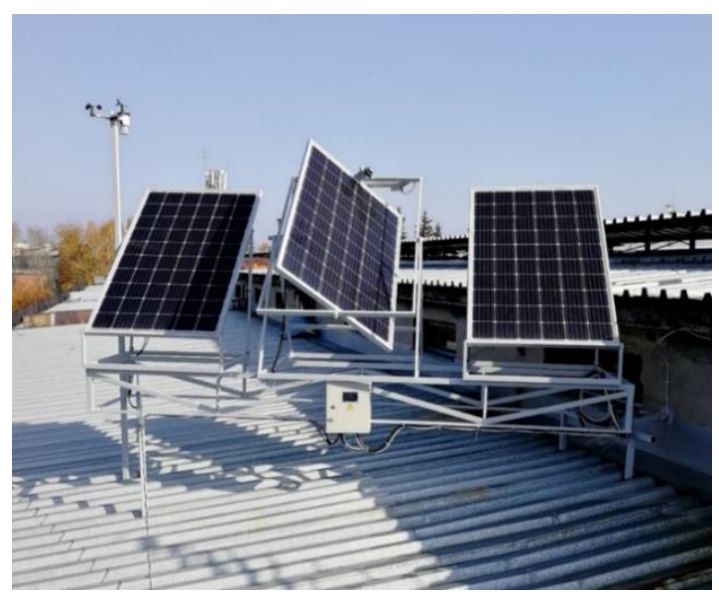

Fig. 1. General view of the main equipment of the experimental array

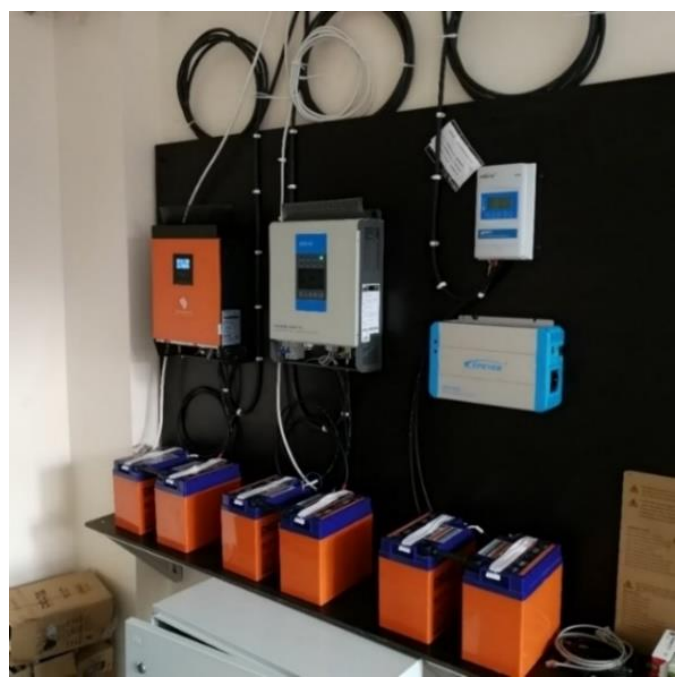

Fig. 2. General view of the auxiliary equipment of the experimental array

The hybrid inverter allows one to get some indicators, such as the total power, over a certain period. The instantaneous values are displayed on the screen. All three inverters used in the array are from different manufacturers, so a comparison of their performance is not feasible. This factor forces the development of a proprietary device for recording the indicator values.

\section{Solar energy meter description}

Obtaining instantaneous current and voltage values in real-time is needed to monitor the power delivered by the solar panel. These readings should be monitored by three identical devices from each individual panel with a different frequency throughout the day and written in the data array. There are shunt wattmeters that can display current, voltage, and power in real-time. However, it is not possible to set the frequency of reading the data and writing the values into memory for further analysis. In addition, these instruments do not have the ability to calibrate three different devices in order to be able to reliably compare data from three different sources.

An intermediate version of the meter designed by the authors based on an Arduino microcontroller and a shunt ammeter is shown in Figure 3. The Arduino microcontroller acts as a central processor for executing the instructions set by the firmware. The shunt ammeter is a device that converts the current data originating from the solar panels. The maximum current the panel can produce is 10 amps.

The power is calculated from the received parameters by means of the microcontroller. This proprietary device makes it possible to set the frequency of data reading and saving the data obtained from the sensors in the form of a file that is convenient for further processing. A screen for displaying instantaneous realtime data is not a required component but is important when debugging the meter to compare readings. 


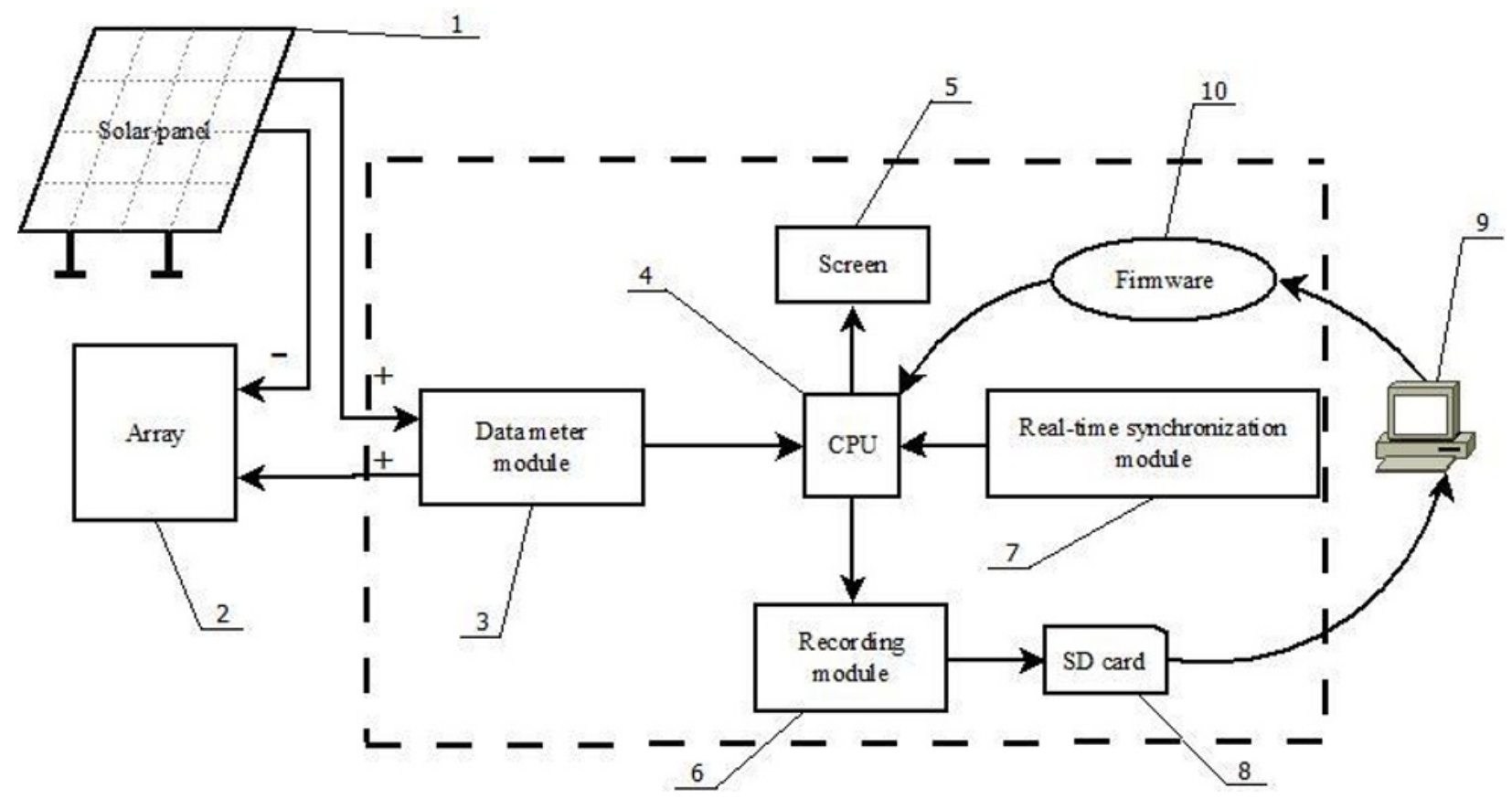

Fig. 4. The structural diagram of the device for data reading

- - - the meter circuit; 1 - solar panel; 2 - auxiliary equipment: charge controllers, storage batteries and current inverters; 3 - shunt ammeter; 4 - Arduino microcontroller; 5 - LCD screen to display instantaneous real-time data; 6 - device that records data from the meter; 7 - quartz real-time clock; 8 - memory card for data storage; 9 computer; 10 - program instructions for CPU.

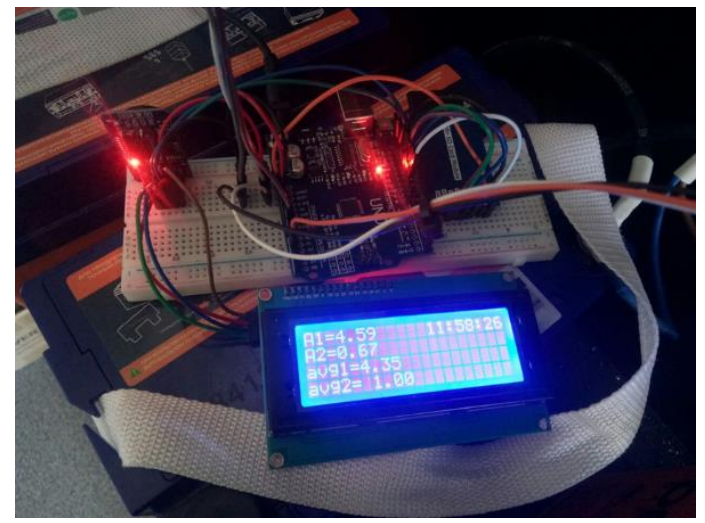

Fig. 3. Meter based on the Arduino microcontroller and shunt ammeter

This device for data reading and writing is connected to the power supply circuit gap and has several blocks that are controlled by the microcontroller. The structural diagram of the device is shown in Figure 4

The data read from the meter are written to the SD card in two files. The first file records instantaneous readings once per minute, the second file records the average of the sensors for the same minute. The time of each measurement is recorded in both files. The SD card is currently used to write the measurement archive and transfer it to a PC for further processing.

The quartz real-time clock records the date and time of the data reading. The clock has a built-in battery, so it retains the values when the power is turned off. The computer is used to write the firmware code and process the received data.

An ACS712 shunt ammeter is used as the current sensor (Fig. 5). The sensor is based on the Hall effect
$[10,11]$. The current sensor converts the received value into a digital signal ranging from 0 to 1023 . This value is converted into current using the "ACS712-arduino-1master" library, which is freely available. To convert the analog signal to digital, a zero value of each sensor and an extra factor are found, depending on the type of the sensor [10].

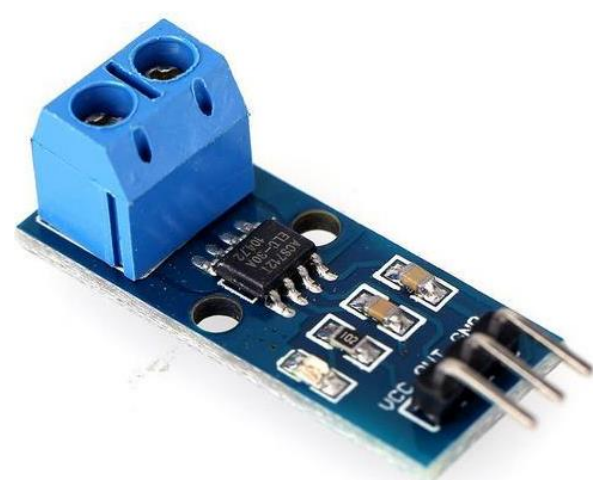

Fig. 5. ACS712 current sensor

It is worth noting that there are several types of ACS712 sensors, and they differ in their sensitivity and maximum measured current, which affects the accuracy of measurements. The meter we have designed uses a sensor of type ACS712-30A, it is designed for high currents, at the same time it has the lowest accuracy. This peculiarity is compensated by the program code, where the sensor values are converted under the assumption that it is ACS712-20A. 


\section{Conclusion}

To read and write data from the solar panels of the experimental array in real-time, the authors have designed a proprietary device that allows one to save information obtained from sensors in the form of a file that is convenient for further processing. Further data processing will be done on the computer and involves the following basic steps:

1. Accumulation of data on the total energy output of each of the panels.

2. Visualization of data in the form of graphs, both for totals and values for a certain period of time.

3. An easy-to-view comparison of instantaneous solar panels power data.

Also, along with writing to a memory card, to ensure the stand-alone reading and storing of the archive of measurements, the transferring and synchronization of data with the server via Wi-Fi several times a day will also be implemented. This feature is very important to reduce the network load when monitoring a large number of signals. The device deisgned by the authors can be used to monitor any parameter or signal for which there is an extension module for the Arduino microcontroller.

The work was supported by the grant №075-152020-787 in the form of a subsidy for a Major scientific project from Ministry of Science and Higher Education of Russia (project "Fundamentals, methods and technologies for digital monitoring and forecasting of the environmental situation on the Baikal natural territory").

\section{References}

1. O.S. Popel, S.V. Kiseleva, M.O. Morgunova, T.S.Gabderakhmanova, A.B. Tarasenko, Using renewable energy sources for electric power supply to consumers in the Arctic zone of the Russian Federation (Arktika: Ekologiya i ekonomika, 1, 6469 2015) (in Russian)

2. I.Yu. Ivanova, T.F. Tuguzova, V.A. Shakirov, N.A. Khalgaeva, Revisiting the issue of the need to take into account various factors when justifying the use of photovoltaic power potential for electric power supply purposes: the case of the Republic of Sakha (Izvestija zRossijskoj akademii nauk. Energetika. 2, 41-54, 2018 ) (in Russian)

3. S.E Frid, N.V. Lisitskaya, O.S. Popel', Results of the analysis of the applicability of satellite observations and re-analysis data for modeling stand-alone solar power plants (Doklady Akademii nauk Vol. 488, 6, 609-611, 2019) (in Russian)

4. The Irkutsk region and the western part of the Buryat ASSR. P. 1. Solar radiation, radiation balance, and sunshine. - Leningrad: Gidrometeoizdat (Handbook on the climate of the USSR, 22. 72, 1966) (in Russian)

5. NASA Prediction of Worldwide Energy Resources. The POWER Project. URL: https://power.larc.nasa.gov/ (Accessed on March 3, 2021).

6. Multiple year data. Parts 1-6. The Irkutsk region and the western part of the Buryat ASSR. Leningrad: Gidrometeoizdat (Scientific and applied handbook on the climate of the USSR. 22, 609, 1991) (in Russian)

7. D. Myers, Solar Radiation: Practical Modeling for Renewable Energy Applications (CRC Press/Taylor \& Francis Group, 182, 2013)

8. M.J. Ahmad, G.N. Tiwari, Solar radiation models A review (International Journal of Energy Research, 35, 271-290, 2011, https://doi.org/10.1002/er.1690)

9. S.V. Mitrofanov, A.Y. Nemaltsev, D.K. Baikasenov, Initial testing of an automated two-coordinate solar tracker in the climatic conditions of the Orenburg region as a prospect of creating a hardware-software system (International Scientific Journal for Alternative Energy and Ecology (ISJAEE), 07-09, 43-54, 2018) (in Russian)

10. A brief overview of Allegro ACS712 current sensor. URL:

https://www.radiolocman.com/shem/schematics.htm 1?di=113339 (Accessed on February 4, 2021).

11. Electronic Components Datasheet Search. URL: https://www.alldatasheet.com/ (Accessed on February 20, 2021) 